\title{
Evaluation of In Vitro Equivalence for Drugs Containing BCS Class II Compound Ketoprofen
}

\author{
I. E. Shohin ${ }^{1,2, *}$, J. I. Kulinich ${ }^{1,2}$, G. V. Ramenskaya ${ }^{1,2}$, and G. F. Vasilenko ${ }^{2}$ \\ 'Sechenov First Moscow State Medical University, 8-2, Trubetskaya Street \\ 119991, Moscow, Russia \\ ${ }^{2}$ Scientific Center for Expertise of Medical Products, Moscow, Russia
}

\begin{abstract}
This paper describes the evaluation of the in vitro equivalence of capsules containing a BCS Class II compound, ketoprofen, marketed in Russia under biowaiver conditions and the innovator product. The in vitro equivalence test was carried out according to WHO Technical Report Series, No. 937, Annex 8. Dissolution profiles of test and reference (innovator) ketoprofen capsules are considered equivalent at $\mathrm{pH} 6.8$ without statistical treatment, equivalent at $\mathrm{pH} 4.5$ $\left(f_{1}=3\right.$ and $\left.f_{2}=80\right)$, and not equivalent at $\mathrm{pH} 1.2\left(f_{1}=22\right.$ and $\left.f_{2}=41\right)$. Generally, the evaluated capsules did not meet biowaiver criteria for drugs containing BCS Class II API, possibly due to the effect of surfactant (sodium lauryl sulfate) contained in the test preparation on the solubility.
\end{abstract}

\section{INTRODUCTION}

$\mathrm{T}$ he dissolution test, at first exclusively a quality control test, is now emerging as a surrogate equivalence test for certain categories of orally administered pharmaceutical products. For some solid dosage forms containing active pharmaceutical ingredients (API) with suitable biopharmaceutical properties, in vitro dissolution profile similarity can be used to establish equivalence of the test product with the reference product. Such studies, used to approve equivalence other than through in vivo equivalence testing, are called "biowaivers" (1). A biowaiver includes dissolution kinetics studies called "in vitro equivalence tests." This term is used in the WHO Technical Report Series, No. 937, Annex 7, and means a dissolution test that includes comparison of the dissolution profile between test product and reference product in three media: $\mathrm{pH} 1.2$, $\mathrm{pH} 4.5$, and $\mathrm{pH} 6.8$. It should be noted that quality control dissolution test conditions differ from in vitro equivalence tests and are not applicable for this purpose (2).

Ketoprofen is an ibuprofen-type, nonsteroidal antiinflammatory drug (NSAID) regarded as a nonselective cyclooxygenase (COX) inhibitor. Ketoprofen is indicated for the treatment of mild to moderate pain related to dysmenorrhea, headache, migraine, postoperative and dental pain, and in the management of spondylitis, osteoarthritis, rheumatoid arthritis, and soft tissue disorders (3). The chemical name of ketoprofen is (RS)-2-(3-benzoylphenyl) propanoic acid. Its structure is shown in Figure 1.

\section{Solubility}

Ketoprofen is described as slightly soluble in water $(4,5)$. Experimental solubility at $\mathrm{pH} 2.0$ is $0.205 \mathrm{mg} / \mathrm{mL}$ (6), and

${ }^{*}$ Corresponding author. the lowest solubility in aqueous solution is $0.010 \mathrm{mg} / \mathrm{mL}$ (7). Within the gastrointestinal $\mathrm{pH}$ range, ketoprofen is an ionized compound (weak acid). The $\mathrm{p} K_{\mathrm{a}}$ of ketoprofen is approximately 4.45 at $25^{\circ} \mathrm{C}$ (8). Thus, ketoprofen solubility increases with $\mathrm{pH}$ and is about $40.76 \mathrm{mg} / \mathrm{mL}$ at $\mathrm{pH} 6.8$ (9). Russia has two Marketing Authorizations (MA) for ketoprofen as immediate-release capsules at a strength of $50 \mathrm{mg}$ and three MAs for ketoprofen as immediate-release tablets at strengths of 25 and $100 \mathrm{mg}$ (10). Thus, the dose/ solubility (D/S) ratio for ketoprofen is less than $250 \mathrm{~mL}$ for the highest dose marketed in Russia, although it dissolves in $250 \mathrm{~mL}$ of buffer solution at $\mathrm{pH}$ 6.8. Therefore, ketoprofen is a "low solubility" drug according to WHO Guidance.

\section{Permeability}

When an API is absorbed to an extent of $85 \%$ or more, it is considered "highly permeable." The absolute bioavailability of ketoprofen is $90 \% ; T_{\max }$ is $1-2 \mathrm{~h}$ after oral administration. The permeability obtained by the method of intestinal perfusion in vivo $\left(P_{\text {eff in vivo }}\right)$ is $8.7 \times 10^{-4} \mathrm{~cm} / \mathrm{s}(6)$. In a Caco- 2 cell culture study, $P_{\text {app }}$ of ketoprofen is $40.6 \times 10^{-6} \mathrm{~cm} / \mathrm{s}$. Its intestinal perfusion in rats $\left(P_{\text {eff in situ }}\right)$ is $1.9 \times 10^{-4} \mathrm{~cm} / \mathrm{s}(11)$. Therefore, ketoprofen is a compound with high permeability according WHO Guidance.

\section{Biopharmaceutical Classification}

Ketoprofen is not listed in the WHO Model list and is not classified according to BCS by WHO (12). Taking ketoprofen solubility (low) and permeability (high) into account, ketoprofen is assigned to BCS Class II according to WHO Guidances.

\section{Biowaiver Eligibility for BCS Class II API}

The BCS Guidance of the United States Department of Health and Human Services, Food and Drug 
<smiles>CC(C(=O)O)c1cccc(C(=O)c2ccccc2)c1</smiles>

Figure 1. Structure of ketoprofen.

Administration (FDA) recommends the biowaiver only for drug products containing Class I compounds (13). Discussions at scientific workshops after the guidance became available and in subsequent publications suggested that biowaivers could be extended to drug products containing Class II and III APIs. WHO Technical Report Series, No. 937, Annex 8 states that biowaivers can apply to Class II weak acids, which are highly soluble at $\mathrm{pH} 6.8$ but not at $\mathrm{pH} 1.2$ or $\mathrm{pH} 4.5$. Ketoprofen fulfills these criteria as described above. Therefore, ketoprofen in vitro equivalence may be evaluated under biowaiver conditions for BCS Class II.

\section{MATHERIALS AND METHODS Chemicals}

Analytical grade concentrated hydrochloric acid, glacial acetic acid, potassium dihydrogen phosphate, disodium hydrogen phosphate dodecahydrate, and potassium chloride were used.

Innovator ketoprofen immediate-release capsules, used as reference product, and a generic version (test product) in strengths of $50 \mathrm{mg}$ marketed in Russia were evaluated.

\section{Apparatus and Procedure}

All dissolution studies were performed using USP Apparatus 2 (Erweka DT 600, Frankfurt, Germany) at 75 rpm. Dissolution media were USP buffer solutions $\mathrm{pH} 1.2$ (hydrochloric acid solution), $\mathrm{pH} 4.5$ (acetate buffer solution), and pH 6.8 (phosphate buffer solution) at $37 \pm$ $0.5^{\circ} \mathrm{C}$. Dissolution medium volume was $500 \mathrm{~mL}$. Twelve capsules of each preparation were studied to evaluate statistical significance of the results. In all experiments, 5 - $\mathrm{mL}$ sample aliquots were withdrawn at 10,15, 20,30, and 45 min using micropipettes and immediately replaced with equal volumes of fresh medium at the same temperature to maintain constant total volume during the test. All samples were filtered through $0.45-\mu \mathrm{m}$ membrane filters. Because the absorbance values of undiluted samples were greater than $1,4.5 \mathrm{~mL}$ of corresponding dissolution medium was added to $0.5 \mathrm{~mL}$ of each sample to obtain valid results. Diluted samples were mixed using a Vortex mixer for $15 \mathrm{~s}$.

Drug release was evaluated spectrophotometrically using a UV-vis spectrophotometer (Agilent 8453, Santa Clara, (A, USA) at $260 \mathrm{~nm}$ using the corresponding dissolution medium as a reference. Ketoprofen CRS solution at $0.01 \mathrm{mg} / \mathrm{mL}$ in the corresponding dissolution medium was used as reference standard solution.
Table 1. Excipients Contained in (1) Reference and (2) Test Drugs

\begin{tabular}{lc}
\hline Excipient & Evaluated Drug \\
\hline Gelatin & 1,2 \\
\hline Indigo carmine FD\&C blue \#2 & 2 \\
\hline Patent blue V & 1 \\
\hline Silica colloidal & 1,2 \\
\hline Croscarmellose sodium & 2 \\
\hline Lactose & 1,2 \\
\hline Magnesium stearate & 1 \\
\hline Sodium lauryl sulfate & 2 \\
\hline Povidone & 2 \\
\hline Titanium dioxide & 1,2 \\
\hline Cellulose & 2 \\
\hline
\end{tabular}

Dissolution profile comparisons were made according WHO Guidances ( 1 ) calculating $f_{1}$ and $f_{2}$ factors. Statistical treatment was carried out using Microsoft Excel software.

\section{Excipients}

The excipients contained in the evaluated drug products are shown in Table 1.

\section{RESULTS AND DISCUSSION}

Biowaiver criteria for drugs containing BCS Class II APIs with weak acid properties and high solubility at $\mathrm{pH} 6.8$ but not at $\mathrm{pH} 1.2$ and $\mathrm{pH} 4.5$ (1) are:

1. The dosage form is rapidly dissolving ( $85 \%$ in $30 \mathrm{~min}$ or less) in $\mathrm{pH} 6.8$ buffer (only).

2. The test product exhibits similar dissolution profiles, as determined by the $f_{2}$ value or equivalent statistical evaluation, to those of the reference product at the

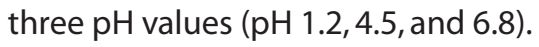

Furthermore, for test products containing Class II APIs with dose/solubility ratios of $250 \mathrm{~mL}$ or less at $\mathrm{pH} 6.8$, the excipients should be critically evaluated in terms of type and amounts (e.g., of surfactants) in the formulation.

Both evaluated drug products are "rapidly dissolving" (see Table 2) at $\mathrm{pH} 6.8$ because the API release at time point $30 \mathrm{~min}$ is greater than $85 \%$.

\section{Table 2. Dissolution Amount for Evaluated Drugs}

\begin{tabular}{ccccccc}
\hline & \multicolumn{2}{c}{ Test Product } & & \multicolumn{2}{c}{ Reference Product } \\
\cline { 2 - 3 } \cline { 5 - 6 } Medium & $\begin{array}{c}\text { \% dissolved } \\
(\bar{X}) \mathbf{1 5} \text { min }\end{array}$ & $\begin{array}{c}\text { \% dissolved } \\
(\bar{X}) \mathbf{3 0 ~} \mathbf{~ m i n}\end{array}$ & & $\begin{array}{c}\text { \% dissolved } \\
(\bar{X}) \mathbf{1 5} \text { min }\end{array}$ & $\begin{array}{c}\text { \% dissolved } \\
(\bar{X}) \mathbf{3 0 ~} \mathbf{~ m i n}\end{array}$ \\
\hline $\mathrm{pH} 6.8$ & 98.0 & 99.4 & 95.0 & 99.5 \\
\hline
\end{tabular}




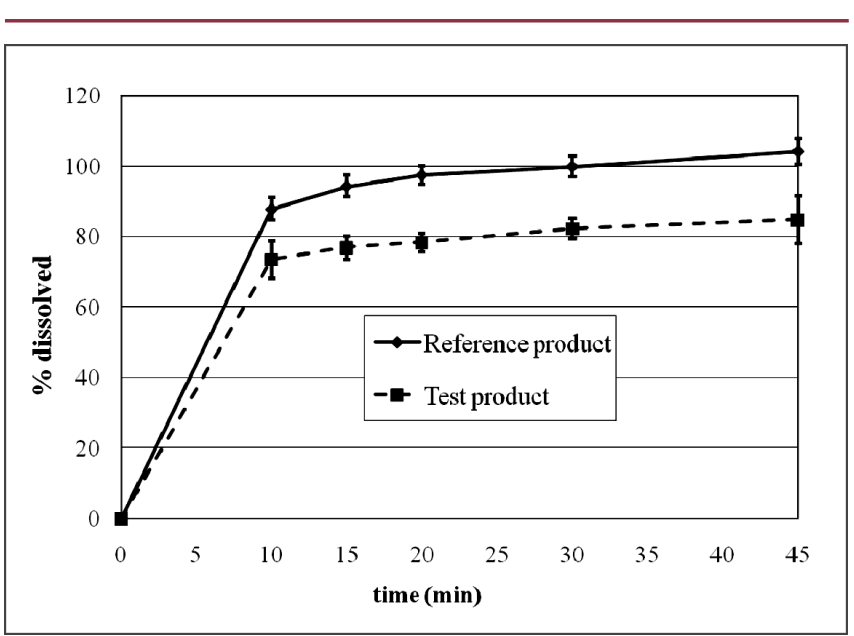

Figure 2. Dissolution profiles of test and reference drugs at pH 1.2.

Dissolution profiles and corresponding data are shown in Figures 2-4 and Table 3. Dissolution profiles in $\mathrm{pH} 6.8$ buffer are similar without statistical treatment (greater than $85 \%$ released after $15 \mathrm{~min}$ ). For $\mathrm{pH} 4.5$, the similarity factor $f_{2}$ value is 80 and factor $f_{1}$ is 3 ; therefore, the dissolution profile of the test product is similar to that of the reference product at this $\mathrm{pH}$. Dissolution profiles in $\mathrm{pH} 1.2$ buffer are considered not similar because the calculated factors $\left(f_{2}=41\right.$ and $\left.f_{1}=22\right)$ do not meet the acceptance criteria $\left(50 \leq f_{2} \leq 100 ; 0 \leq f_{1} \leq 15\right)$. The surfactant (sodium lauryl sulfate) contained in the test preparation possibly increased the ketoprofen solubility, which caused the dissolution profile dissimilarity. The addition of sodium lauryl sulfate in concentrations of $0.5-2 \%$ significantly increases the solubility of ketoprofen, especially at low $\mathrm{pH}$, from about 5 to about 30 times that at $\mathrm{pH} 4.6$, respectively (9). Therefore, the presence of surfactants increases the release rate of ketoprofen and improves its dissolution. However, such differences in test and reference drug products do not seem to be critical, because improved dissolution in acidic medium with sodium lauryl sulfate

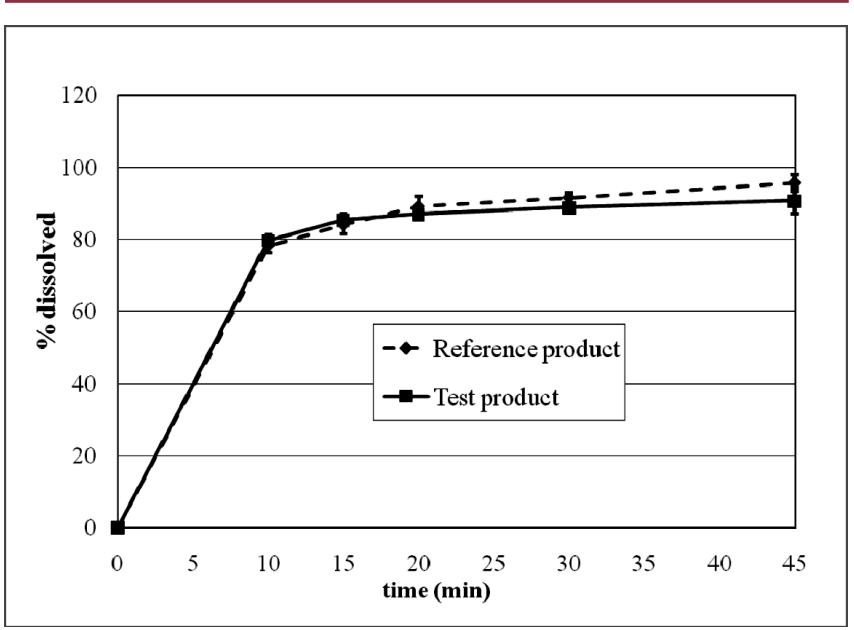

Figure 3. Dissolution profiles of test and reference drugs at $\mathrm{pH} 4.5$.

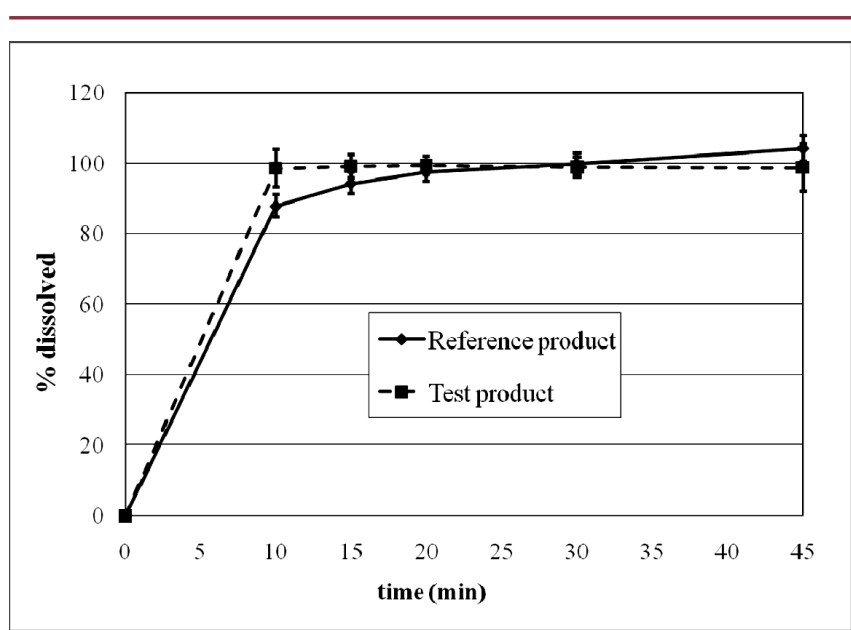

Figure 4. Dissolution profiles of test and reference drugs at $\mathrm{pH} 6.8$.

would not cause bioinequivalence of evaluated products, only in vitro inequivalence. In addition, because of the high permeability of ketoprofen, its low solubility at pH 1.2 does not pose a serious risk for bioinequivalence. This acidic medium may be "over discriminatory" for in vitro equivalence evaluation of ketoprofen drug products.

The percent relative standard deviation (\% RSD) for all time points fulfills all requirements ( $\leq 20 \%$ for first time point, $\leq 10 \%$ for other time points), so obtained results are valid (see Table 2).

Table 3. Dissolution Test Results

\begin{tabular}{|c|c|c|c|c|c|}
\hline \multirow[b]{2}{*}{ Medium } & \multirow[b]{2}{*}{ Time (min) } & \multicolumn{2}{|c|}{ Test Product } & \multicolumn{2}{|c|}{ Reference Product } \\
\hline & & $\begin{array}{l}\text { \% dissolved } \\
(\bar{X})\end{array}$ & $\begin{array}{l}\text { RSD } \\
\text { (\%) }\end{array}$ & $\begin{array}{c}\text { \% dissolved } \\
(\bar{X})\end{array}$ & $\begin{array}{l}\text { RSD } \\
\text { (\%) }\end{array}$ \\
\hline \multirow[t]{5}{*}{$\mathrm{pH} 1.2$} & 10 & 70.8 & 4.0 & 47.2 & 1.7 \\
\hline & 15 & 74.3 & 4.2 & 56.4 & 2.9 \\
\hline & 20 & 76.2 & 5.7 & 63.8 & 3.0 \\
\hline & 30 & 79.7 & 3.0 & 69.1 & 2.6 \\
\hline & 45 & 81.8 & 2.1 & 76.4 & 1.1 \\
\hline \multirow[t]{5}{*}{$\mathrm{pH} 4.5$} & 10 & 79.8 & 1.6 & 77.5 & 1.9 \\
\hline & 15 & 85.0 & 1.7 & 83.7 & 2.5 \\
\hline & 20 & 87.2 & 0.8 & 89.5 & 2.8 \\
\hline & 30 & 88.9 & 0.7 & 91.5 & 1.4 \\
\hline & 45 & 92.2 & 3.5 & 95.3 & 2.4 \\
\hline \multirow[t]{5}{*}{$\mathrm{pH} 6.8$} & 10 & 96.7 & 3.2 & 87.9 & 5.3 \\
\hline & 15 & 98.0 & 3.1 & 95.0 & 3.3 \\
\hline & 20 & 98.9 & 2.6 & 97.3 & 2.6 \\
\hline & 30 & 99.4 & 2.9 & 99.5 & 2.8 \\
\hline & 45 & 99.9 & 3.6 & 104.2 & 6.7 \\
\hline
\end{tabular}




\section{CONCLUSION}

The evaluated ketoprofen drug product does not fulfill biowaiver criteria for drug products containing BCS Class II APIs. Both drug products are "rapidly dissolving," but they do not meet the criteria for dissolution profile similarity, $f_{1}$ and $f_{2}$. The dissolution profile of the test product is similar to that of the reference product in $\mathrm{pH} 4.5$ and 6.8 buffers but not similar in $\mathrm{pH} 1.2$ buffer using the paddle method at $75 \mathrm{rpm}$. Thus, these products are considered in vitro inequivalent. However, other immediate-release dosage forms of ketoprofen may be evaluated using in vitro equivalence testing.

\section{REFERENCES}

1. WHO Expert Committee on Specifications for Pharmaceutical Preparations. WHO Technical Report Series, No. 937, Annex 8. Proposal to waive in vivo bioequivalence requirements for WHO Model List of Essential Medicines immediate-release, solid oral dosage forms; World Health Organization: Geneva, Switzerland, 2006.

2. WHO Expert Committee on Specifications for Pharmaceutical Preparations. WHO Technical Report Series, No. 937, Annex 7. Multisource (generic) pharmaceutical products: guidelines on registration requirements to establish interchangeability; World Health Organization: Geneva, Switzerland, 2006.

3. Ketoprofen prescribing information, Lek Pharmaceuticals d. d., Slovenia, 2007.

4. United States Pharmacopeia and National Formulary USP 29-NF 24; The United States Pharmacopeial Convention, Inc.: Rockville, MD, 2006.

5. European Pharmacopoeia, 6th ed.; European Directorate for the Quality of Medicines, Council of Europe: Strasbourg, France, 2007.
6. Tubic-Grozdanis, M.; Bolger, M.; Langguth, P. Application of Gastrointestinal Simulation for Extensions for Biowaivers of Highly Permeable Compounds. AAPS J. 2008, 10 (1), 213-226.

7. Therapeutic Systems Research Laboratories; Biopharmaceutics Classification System (BCS) search engine. http://69.20.123.154/services/bcs/search.cfm (accessed Jan 19, 2011).

8. Drug Bank database. Drug card for Ketoprofen. http:// www.drugbank.ca/drugs/DB01009 (accessed Jan 19, 2011).

9. Sheng, J.; Kasim, N. A.; Chandrasekharan, R.; Amidon, G. L. Solubilization and dissolution of insoluble weak acid, ketoprofen: Effects of $\mathrm{pH}$ combined with surfactant. Eur. J. Pharm. Sci. 2006, 29, 306-314.

10. FGU NCESMP Roszdravnadzor database. http://www. regmed.ru (accessed Jan 13, 2011).

11. Hilfinger, J. Permeability Classification... In vitro and in situ methodology. Presented at the AAPS Workshop on BE, BCS and Beyond, Bethesda, MD, May 21, 2007. http://www.aapspharmaceutica.com/meetings/ files/90/13Hilfinger.pdf (accessed Jan 18, 2011).

12. WHO Expert Committee on Specifications for Pharmaceutical Preparations. WHO Model List of Essential Medicines, 15th list; World Health Organization: Geneva, Switzerland, 2007.

13. Waiver of In Vivo Bioavailability and Bioequivalence Studies for Immediate-Release Solid Oral Dosage Forms Based on a Biopharmaceutics Classification System; Guidance for Industry; U.S. Department of Health and Human Services, Food and Drug Administration, Center for Drug Evolution and Research (CDER). U.S. Government Printing Office:Washington, DC, August 2000. 